Trinity University

Digital Commons @ Trinity

Health Care Administration Faculty Research

Health Care Administration

9-2017

\title{
Clustered and Distinct: A Taxonomy of Local Multihospital Systems
}

Patrick D. Shay

Trinity University, pshay@trinity.edu

Stephen S. Farnsworth Mick

Follow this and additional works at: https://digitalcommons.trinity.edu/hca_faculty

Part of the Medicine and Health Sciences Commons

\section{Repository Citation}

Shay, P. D., \& Mick, S. S. F. (2017). Clustered and distinct: A taxonomy of local multihospital systems. Health Care Management Science, 20(3), 303-315. http://doi.org/10.1007/s10729-016-9353-7

This Post-Print is brought to you for free and open access by the Health Care Administration at Digital Commons @ Trinity. It has been accepted for inclusion in Health Care Administration Faculty Research by an authorized administrator of Digital Commons @ Trinity. For more information, please contact jcostanz@trinity.edu. 


\section{Clustered and distinct: a taxonomy of local multihospital systems}

Health Care Management Science | Manuscript Draft

Patrick D. Shay ${ }^{1}$ - Stephen S. Farnsworth Mick ${ }^{2}$

${ }^{1}$ Department of Health Care Administration, Trinity University

One Trinity Place, \#58, San Antonio, TX, 78212 USA • pshay @trinity.edu

2 Department of Health Administration, School of Allied Health Professions

Virginia Commonwealth University, P.O. Box 980203, Richmond, VA, 23298

\section{Abstract}

Despite their prevalence and power in markets throughout the United States, local multihospital systems (LMSs) - also referred to as hospital-based "clusters" - remain an understudied organizational form, with studies instead primarily focusing either upon individual hospitals or viewing hospital systems collectively without distinguishing the local "sub-systems" that comprise larger regional or national hospital chains. To better understand these organizational forms, we develop a taxonomy specifically devote to LMSs, applying taxonomic analysis methods to a sample of LMSs in six U.S. states while accounting for LMSs' geographic arrangements and nonhospital-based service locations. Our analysis identifies five distinct LMS categories, with forms clearly distinguished according to their varying degrees of differentiation and integration. The study's results accentuate the importance of accounting for hospital systems' activities and arrangements in local markets - including their non-hospital-based sites - and highlight differences in systems' achievement of integration and coordination across services and locations, providing considerations in light of U.S. health system reform as well as international patterns of regional system formation.

Keywords

Local multihospital systems $\bullet$ Differentiation Integration Configuration • Coordination $•$ Taxonomy 


\section{Introduction}

Local health care markets throughout the U.S. typically include one or more multihospital systems, recognized by their ownership and operation of two or more hospitals within proximate geographic areas. These local multihospital systems (LMSs), also referred to as hospital-based "clusters," include systems contained within a single metropolitan area as well as "subsystems" of regional or national hospital chains operating within a specific local market, and they now represent the majority of general acute care hospitals [1].

Despite their dominance, LMSs remain understudied because research often fails to distinguish local multihospital systems, grouping together multihospital chains operating across multiple markets with those in a single local area $[2,3]$. Studies have seldom explicitly examined LMSs as an organizational form, but of the exceptions, researchers point to the potential for LMSs to improve care coordination and service rationalization given their proximate spatial arrangements [4-7]. At the same time, these scholars have challenged LMSs' progress in realizing such potential, leading us to ask, to what degree do today's LMSs integrate and coordinate the delivery of care across their services and locations?

Answering this question requires a deeper understanding of LMSs' forms, including their diverse structures, service configurations, physical arrangements, and behavioral patterns. Although anecdotal evidence suggests LMSs "vary dramatically from one another, both within and across markets" [7: 42], empirical classification of LMS forms has remained nonexistent in the literature. Such classification would recognize both common features and key differences among LMS forms, addressing problems of underidentification or overidentification, respectively [8], and would answer calls for taxonomic analysis of LMSs [1,6]. Given this knowledge gap, our study develops a taxonomy describing and categorizing LMS forms.

Our study is distinct from previous taxonomic efforts of hospital systems [e.g., 9, 10] as it is the first taxonomy focused upon local multihospital systems, incorporating proximity for defining multihospital systems. This 
distinction permits the comparison of forms observed between different LMSs even within a single multihospital chain, recognizing that health care remains primarily local in nature $[4,11]$. In contrast to previous research, this study also examines spatial differentiation when classifying hospital systems and accounts for LMSs' hospital- and non-hospital-based service locations, reflecting local systems" "geographic expansion race" to develop and disperse new hospital facilities and freestanding non-hospital-based sites throughout local markets [12]. And, whereas previous taxonomic studies used hospital data before 2000, this study utilizes more recent data, reflecting the current health care system landscape and the myriad developments in the hospital industry since the beginning of the 21 st century.

\section{Theoretical framework}

Taxonomic analysis requires a theoretical framework identifying characteristics across subgroups [13]. Contingency theory describes differentiation and integration as "environmentally required states" confronting each organization and influencing its effectiveness, with organizational forms described according to varying levels of differentiation and integration as they adopt structures that best fit the demands of their tasks and environments [14: 132]. Similarly, strategic management theory recognizes configuration and coordination as key dimensions characterizing firms' strategic activities, allowing them to fit environmental demands with internal competencies to achieve competitive advantage [15]. Luke and Ozcan [1] noted the complementarity between differentiation and configuration as well as integration and coordination, explaining that they collectively account for improved performance afforded by spatially proximate relations and geographic arrangements.

Scholars have distinguished numerous forms of differentiation, including horizontal, vertical, and spatial differentiation. Mileti and colleagues [16: 210] defined horizontal differentiation as "the number of services or jobs performed" by an organization. In health care, this relates to the number and type of patient services. In contrast, vertical differentiation accounts for the hierarchical ranking of organizational services or functions [16, 17]. For 
health care organizations, this refers to qualitative variation in the complexity or level of care offered among organizational units $[3,18]$. Together, these concepts have also been collectively referred to as service or product differentiation [e.g., 9, 11]. Another source of organizations' distinctiveness is spatial differentiation, defined as the number and geographic dispersion of organizations' physical locations [11,17]. This definition is like Porter's [15] description of configuration: where and in how many sites an organization's value chain activities are located. We treat spatial differentiation and configuration as equivalent concepts ${ }^{1}$ that complement both horizontal and vertical strategies, recognizing "activities can be dispersed geographically according to either vertical or horizontal functions" [22: 137]. The spatial arrangement and proximate geographic positioning of organizational units provides the enhanced opportunity to develop interdependent relationships and complementarities across fellow organizational locations; that is, horizontal and vertical strategies of differentiation and integration may benefit as a result of spatial proximity in local markets, aiding rationalization, promoting cooperation, and amplifying organizational performance through optimal configurations $[1,3,11]$. Thus, we anticipate that the levels of horizontal, vertical, and spatial differentiation exhibited by LMSs vary, serving as distinguishing characteristics across LMS forms.

As organizations engage in increasing levels of differentiation, they grow in their complexity; in turn, the opportunity and value of enhanced coordination and integration increase [22]. Integrative activities have typically been described as horizontal or vertical. Horizontal integration is the combination of organizations with substitutable outputs, which health care studies frequently operationalize as the joining of multiple hospitals under common ownership [23, 24]. Gillies and colleagues [25] noted that horizontal integration in health care also occurs in non-hospital settings, referring to same-stage activities and units in the continuum of care. In contrast, vertical integration describes connections of non-substitutable components across successive stages to produce a final product, which in health care is the provision of health services $[24,26]$. Just as integration follows the increased complexity resulting from differentiation, Porter argues that configuration precedes coordination, which provides unity and structural arrangement to an 
organization's interdependent tasks and components spread across proximate organizational units $[1,15]$. In this sense, coordination as an integrative activity focuses on spatial considerations, examining how and where an organization's activities are aligned across multiple locations. For example, organizations displaying high levels of coordination link activities and exhibit consistencies across firm locations, reducing redundant operations, whereas organizations with low or no coordination operate sites that work independently and appear very different from one another [27]. We expect that LMSs' horizontal integration, vertical integration, and coordination efforts will vary, distinguishing common LMS forms.

The examination of LMSs' horizontal and vertical arrangements requires a disaggregated view of their components. Thus, we adapt previous depictions of the continuum of care in the health care organization literature $[23,26,28$, 29] to generate Figure 1, illustrating the varied services and stages that LMSs may include throughout their structures. ${ }^{2}$ Figure 1 assumes that, within local health care systems, differentiation and integration strategies apply not only at general, acute care hospitals but also at less commonly considered points in the continuum of care such as short-term rehabilitation and nursing sites (e.g., inpatient rehabilitation facilities and behavioral health hospitals), among others. Conversely, outpatient care occurs within hospital facilities as well as at non-hospital-based acute outpatient care settings such as freestanding ambulatory surgery centers. We employ Fig. 1 not only as a conceptual depiction of the continuum of care but also as a measurement system for certain classification variables, discussed later. 
Fig. 1.

The continuum of care ${ }^{2}$

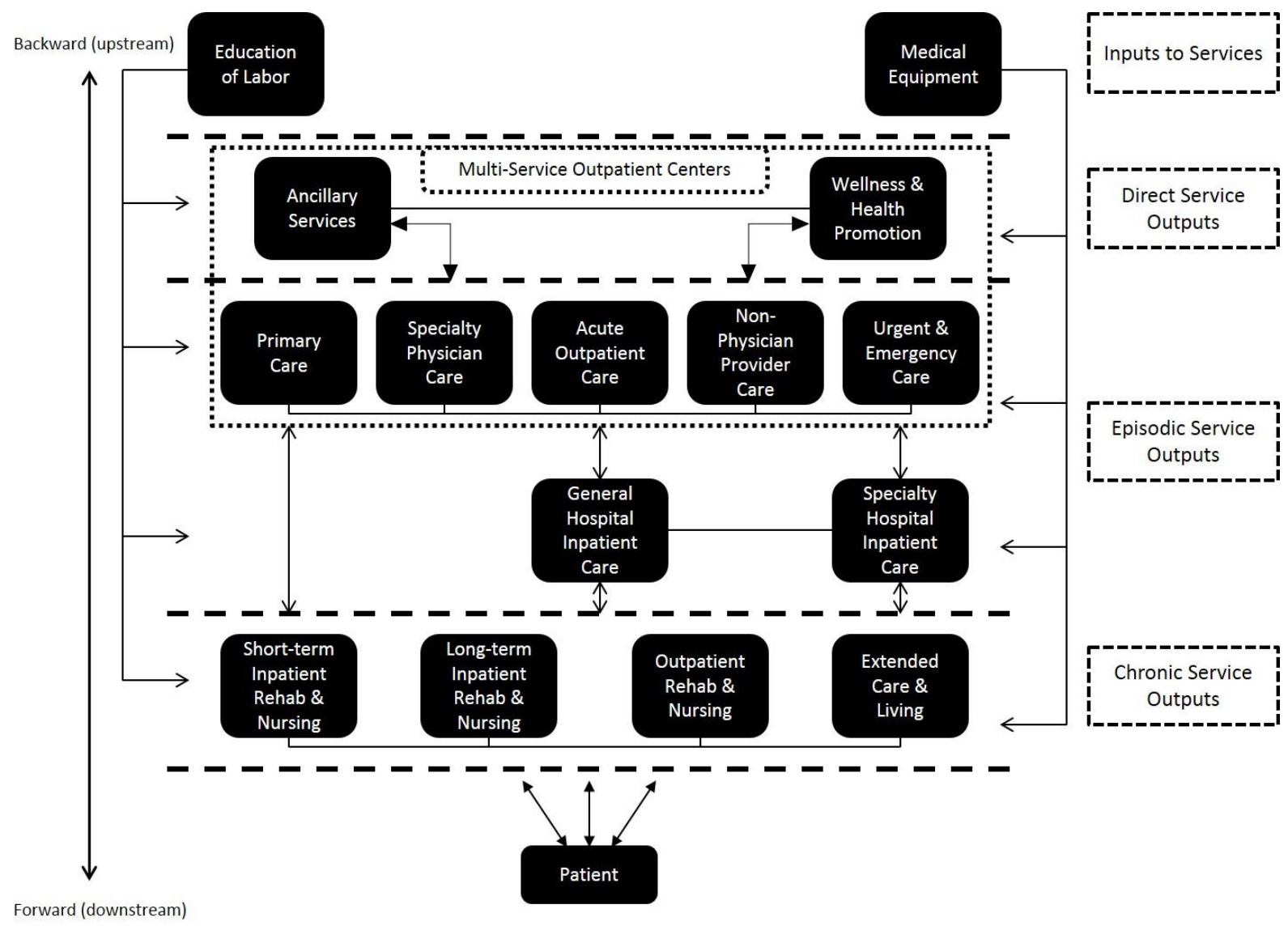

\section{Methods}

This study's unit of analysis is the LMS, defined as "two or more samesystem hospitals located in the same local market or region" [6:253]. Although LMSs' local markets have previously been defined according to urban boundaries, evidence suggests that a broader definition - accounting for same-system hospitals within a specified radius of the local system's largest, or "lead," hospital - more accurately reflects a hospital's LMS membership, as urban boundary definitions underreport both the number and size of LMSs, particularly those that extend into nearby rural areas within their local market [1]. Therefore, adopting the boundary radius modeled in previous studies [e.g., 3], we define LMS boundaries as two or more samesystem hospitals operating within 150 miles of the largest same-system 
hospital, as measured by bed size. Distance between LMS locations is measured using drive distance measurements and calculated using the Google Maps web mapping service application. This approach provides a more precise measurement of spatial relations, accounting for topological structures and road networks that may create barriers affecting geographical access [30].

\subsection{Data sources}

We updated a 2009 national inventory of U.S. LMSs to reflect hospitals' LMS membership as of 2012, following methods described in previous LMS studies [5, 6], which referenced hospital system websites and promotional materials as well as the American Hospital Association (AHA) Annual Survey dataset.

Measures of LMSs' levels of differentiation and integration were based on two secondary datasets - the AHA Annual Survey and the Intellimed datasets - as well as a unique catalog of LMSs' hospital- and non-hospital-based sites as of 2012. The AHA Annual Survey dataset consists of data for all hospitals in the U.S., including information regarding hospitals' organizational characteristics, services, ownership, and location. Additionally, the Intellimed dataset consists of all-payer admission and discharge information reported for individual facilities on a statewide basis, including admissions sources, case mix indices, and conditions, among others. Because our access to Intellimed's hospital admissions dataset was limited to six U.S. states, our study's examination of LMS forms consists of a convenience sample of LMSs in Florida, Maryland, Nevada, Texas, Virginia, and Washington.

Primary data collection from hospital system websites and promotional materials determined each LMS's number, physical address, and type of service locations in the study's six-state convenience sample, as well as the number of beds operated by each general, acute care hospital within each LMS and the distances between a LMS's non-hospital-based sites and its hospital members. Each LMS's care delivery sites were categorized according to one of the fifteen stages within the continuum of care (Fig. 1). Many LMSs operate multi-service outpatient centers (MSOCs), in which a 
range of ambulatory services across multiple stages (e.g., diagnostic imaging, fitness and wellness, primary care, outpatient rehabilitation) are provided at a single location. Rather than categorize MSOCs according to a single service, they are identified as a distinctive service location type and stage in the continuum of care.

Hospital-level data from the AHA 2011 Annual Survey were aggregated to the LMS level, providing information on each LMS's hospital-based service offerings. In some instances, 2011 service data were not provided for individual hospital facilities, and for these observations AHA 2010 Annual Survey data, if available, were substituted. Similarly, we aggregated hospital-level admissions data from the Intellimed dataset to the LMS level. Such data included hospitals' case mix index, number of cases categorized at the highest level for severity of illness (i.e., "extreme"), and number of cases from various admissions sources. For five of the study sample's six states, Intellimed data were available from the 2012 calendar year, but for Texas, data were limited to admissions from July 2011 through June 2012. Data from each of these primary and secondary sources were merged to create a unique LMS dataset. ${ }^{3}$

\subsection{Variable measurements}

Horizontal differentiation pertains to the number of services across system hospitals [9], measured as each LMS's total percentage of services among member facilities and calculated by dividing the number of services offered within a LMS by 151, the total possible number of services to report in the 2011 AHA Annual Survey. A second measure of horizontal differentiation includes each LMS's number of different freestanding service location types, as identified through primary data collection and previously described in the explanation of Fig. $1 .^{2}$

We measure vertical differentiation as the difference in the case mix index of a LMS's lead hospital and the average case mix index of its non-lead hospital members [31]. To identify LMSs that distribute a disproportionate share of complex, high severity cases to lead facilities, this study also measures vertical differentiation as the difference between a lead hospital's percentage 
of cases categorized as "extreme" and the average percentage of "extreme" cases seen by its non-lead LMS hospitals. The Intellimed dataset recognizes "extreme" cases as those assigned the highest severity of illness subclass according to the All Patient Refined Diagnosis Related Groups (APR-DRG) Classification System, with severity of illness gauging the extent of physiologic decompensation or organ system loss of function. Beyond hierarchical distribution of complex cases, LMSs may also exhibit vertical differentiation by the type of care offered among LMS facilities, with specific service lines or clinical conditions at certain hospitals within the LMS [3]. The Intellimed dataset includes hospital admissions by birth, allowing for identification of LMSs that designate specific hospitals as specializing in maternity services; hence, a vertical differentiation proxy by case type uses a LMS's standard deviation of its hospitals' number of childbirths as a percentage of their total admissions.

To capture each LMS's spatial differentiation, we calculate each LMS's count of unique service locations [31]. In addition, LMSs' spatial differentiation includes two measures of the distance between LMS member locations [7], identifying a LMS's geographic "reach" (the average distance in miles between its unique service location sites and its lead hospital) and its geographic "spread" (the average distance between each of a LMS's unique service location sites and its nearest general, acute care hospital member).

We measure horizontal integration as the number of general, acute care hospitals owned and operated by the organization [23]. A second measure of horizontal integration is the number of stages throughout the continuum of care in which a LMS operates multiple care delivery sites other than general, acute care hospitals [25], with each LMS's service locations categorized as a specific site type within a continuum of care stage (Fig. 1). A third measure is the average number of freestanding sites among each LMS's horizontally integrated stages, not including the number of general, acute care hospitals.

The first measure of vertical integration is the number of different stages (Fig. 1) in which a LMS maintains a service location. We assigned each of the 151 service variables in the 2011 AHA Annual Survey dataset as well as each type of service location to a specific stage in the continuum of care [cf. 9, 32, 33). ${ }^{4}$ We also measure LMSs' vertical integration breadth as the 
number of services stemming from acute care hospitals' referral sources (i.e., "upstream") and extending to their placement channels (i.e., "downstream") [28]. "Upstream" vertical integration breadth is the percentage of services provided by a LMS's facilities out of a possible 90 service variables categorized before general, acute inpatient care in the care continuum. "Downstream" vertical integration breadth is the percentage of services provided by a LMS's facilities out of a possible 22 service variables in the post-acute domain of the care continuum. Collectively, "upstream" and "downstream" vertical integration activities allow LMSs to serve patients and direct their flow throughout the continuum of care, linking services flowing to and from the LMSs' core operations - that is, their hospitals [26, 28, 29].

Coordination among LMS hospitals includes the referral of specific cases to lead facilities, exhibiting varying interdependence for patients requiring specialized resources [1], and measured as the difference between a LMS's percentage of referral admissions at its lead hospital and the average percentage of referral admissions among its non-lead hospital members. We also measure coordination as a LMS's average service duplication proportion, calculated by averaging the percentages of member hospitals offering an individual service [7]. Highly coordinated organizations reduce redundancies across their multiple sites, while less coordinated firms tend to duplicate operations across units [27].

This study developed 16 variables to classify LMS forms, with eight variables relating to differentiation and another eight variables relating to integration (Table 1). 


\section{Table 1}

\section{Taxonomic analysis classification variables}

\begin{tabular}{|c|c|c|c|}
\hline Construct & Variable & Measure & $\begin{array}{l}\text { Data } \\
\text { Source }\end{array}$ \\
\hline \multirow[t]{2}{*}{$\begin{array}{l}\text { Horizontal } \\
\text { Differentiation }\end{array}$} & Hospital Services & $\begin{array}{l}\text { The collective number of a LMS's services offered across } \\
\text { member hospitals, as a percentage of } 151 \text { surveyed services }\end{array}$ & $\begin{array}{l}\text { AHA Annual } \\
\text { Survey }\end{array}$ \\
\hline & Service Location Types & $\begin{array}{l}\text { The number of different types of service locations operated by } \\
\text { a LMS }\end{array}$ & $\begin{array}{l}\text { Primary Data } \\
\text { Collection }\end{array}$ \\
\hline \multirow[t]{3}{*}{$\begin{array}{l}\text { Vertical } \\
\text { Differentiation }\end{array}$} & Case Mix Difference & $\begin{array}{l}\text { The difference between a LMS's lead hospital case mix and the } \\
\text { average case mix of its non-lead hospitals }\end{array}$ & Intellimed \\
\hline & Extreme Case Share & $\begin{array}{l}\text { The difference between a LMS's percentage of admissions } \\
\text { categorized as "extreme" cases at its lead hospital and the } \\
\text { average percentage of admissions categorized as "extreme" at } \\
\text { its non-lead hospitals }\end{array}$ & Intellimed \\
\hline & Birth Case Distribution & $\begin{array}{l}\text { The standard deviation of childbirths as a percentage of total } \\
\text { admissions across a LMS's member hospitals }\end{array}$ & Intellimed \\
\hline \multirow[t]{3}{*}{$\begin{array}{l}\text { Spatial } \\
\text { Differentiation }\end{array}$} & Locations & The number of unique service locations operated by a LMS & $\begin{array}{l}\text { Primary Data } \\
\text { Collection }\end{array}$ \\
\hline & Geographic Reach & $\begin{array}{l}\text { The average distance, in miles, between a LMS's unique } \\
\text { service locations and its lead hospital }\end{array}$ & $\begin{array}{l}\text { Primary Data } \\
\text { Collection }\end{array}$ \\
\hline & Geographic Spread & $\begin{array}{l}\text { The average distance, in miles, between a LMS's unique } \\
\text { service locations and that location's nearest general, acute } \\
\text { care member hospital }\end{array}$ & $\begin{array}{l}\text { Primary Data } \\
\text { Collection }\end{array}$ \\
\hline \multirow[t]{3}{*}{$\begin{array}{l}\text { Horizontal } \\
\text { Integration }\end{array}$} & Hospitals & $\begin{array}{l}\text { The number of general, acute care hospitals owned and } \\
\text { operated by a LMS }\end{array}$ & $\begin{array}{l}\text { Primary Data } \\
\text { Collection }\end{array}$ \\
\hline & $\begin{array}{l}\text { Horizontally Integrated } \\
\text { Stages }\end{array}$ & $\begin{array}{l}\text { The number of stages in the continuum of care in which a LMS } \\
\text { operates multiple care delivery sites, excluding general, acute } \\
\text { care hospitals }\end{array}$ & $\begin{array}{l}\text { Primary Data } \\
\text { Collection }\end{array}$ \\
\hline & $\begin{array}{l}\text { Locations Per Horizontally } \\
\text { Integrated Stage }\end{array}$ & $\begin{array}{l}\text { The average number of unique service locations among a } \\
\text { LMS's horizontally integrated stages }\end{array}$ & $\begin{array}{l}\text { Primary Data } \\
\text { Collection }\end{array}$ \\
\hline \multirow[t]{3}{*}{$\begin{array}{l}\text { Vertical } \\
\text { Integration }\end{array}$} & Vertically Integrated Stages & $\begin{array}{l}\text { The number of stages in the continuum of care in which a LMS } \\
\text { operates a service location or provides a service }\end{array}$ & $\begin{array}{l}\text { AHA Annual } \\
\text { Survey / Primary } \\
\text { Data Collection }\end{array}$ \\
\hline & $\begin{array}{l}\text { Upstream Vertical Integration } \\
\text { Breadth }\end{array}$ & $\begin{array}{l}\text { The collective number of a LMS's "upstream" services offered } \\
\text { across member hospitals, as a percentage of } 90 \text { surveyed } \\
\text { services categorized as "upstream" }\end{array}$ & $\begin{array}{l}\text { AHA Annual } \\
\text { Survey }\end{array}$ \\
\hline & $\begin{array}{l}\text { Downstream Vertical } \\
\text { Integration Breadth }\end{array}$ & $\begin{array}{l}\text { The collective number of a LMS's "downstream" services } \\
\text { offered across member hospitals, as a percentage of } 22 \\
\text { surveyed services categorized as "downstream" }\end{array}$ & $\begin{array}{l}\text { AHA Annual } \\
\text { Survey }\end{array}$ \\
\hline \multirow[t]{2}{*}{ Coordination } & Hospital Transfer Difference & $\begin{array}{l}\text { The difference between a LMS's percentage of admissions } \\
\text { classified as transfers or admissions from other hospitals at its } \\
\text { lead hospital and the average percentage of admissions } \\
\text { classified as transfers or admissions from other hospitals } \\
\text { among its non-lead hospitals }\end{array}$ & Intellimed \\
\hline & Duplication of Services & $\begin{array}{l}\text { The average proportion of a LMS's member hospitals providing } \\
\text { a given service across all of the LMS's services. }\end{array}$ & $\begin{array}{l}\text { AHA Annual } \\
\text { Survey }\end{array}$ \\
\hline
\end{tabular}




\subsection{Taxonomic analysis}

Taxonomic analysis began with the selection of classification variables from an explicit theoretical framework [13], as previously described. Mahalanobis distance measures were evaluated across observations, applying a 0.001 significance level to evaluate potential outliers. Classification variables were evaluated for multicollinearity, and the appropriateness of each variable was examined using principal components analysis methods to test whether variables were representative of underlying dimensions. Variables were then standardized, and multiple hierarchical cluster analyses were performed applying squared Euclidean distance measures, allowing for the comparison of results from single-linkage, complete-linkage, average linkage, and Ward's method clustering algorithms. We used multiple cluster determination techniques, examining changes in agglomeration coefficients, dendrograms, and agglomeration plots to identify the optimal number of clusters in the hierarchical cluster analyses. By evaluating each hierarchical algorithm's solution, including comparison of agreement between each pair of solutions using the Hubert-Arabie [34] adjusted Rand index (ARI $\mathrm{HA}_{\mathrm{HA}}$, an optimal hierarchical cluster solution was identified.

A two-stage approach used the results of the optimal hierarchical solution as initial cluster centroids for a nonhierarchical cluster analysis [35, 36]. The final $K$-means cluster solution was tested for reliability through comparison of results across multiple cluster analyses, including solutions from the hierarchical algorithms and solutions using different approaches to address variable standardization and multicollinearity. Simple classification agreement rates and $\mathrm{ARI}_{\mathrm{HA}}$ scores were determined between the final and alternate cluster solutions to evaluate reliability. Additionally, we applied multiple discriminant analysis methods, a common internal validation technique for cluster analysis solutions. The characteristics of each taxonomic group were then compared using analysis of variance (ANOVA) and pairwise multiple comparison methods to examine the degree to which taxonomic groups differed across conceptual dimensions. The interpretation of these groups serves as a validation technique of the final taxonomic analysis solution [13]. 


\section{Results}

Among 840 hospitals in Florida, Maryland, Nevada, Texas, Virginia, and Washington in 2012, $59 \%$ (496) participated in LMSs based within these states, collectively representing 125 LMSs. Of these 125 local systems, a total of 117 LMSs - operating 489 general, acute care hospitals - provided sufficient data to be included in the sample. Compared to the U.S. population of LMSs, the sampled LMSs are comparable in size but more likely to be forprofit and operate solely within urban boundaries. Ownership form and urban versus rural location averages between the sample's LMSs and the total number of LMSs operating in the six-state group do not differ at statistically significant levels.

Mahalanobis distance measures identified three LMSs with distance measures significantly different from the remaining sample at the 0.001 level. Analysis also revealed considerable differences between these outlier observations across different measures, causing their elimination from the analysis. Multicollinearity led to the removal of the hospital services and service location variables. Thus, the taxonomic analysis was performed using 14 variables across a final sample of 114 LMSs.

Principal component analysis indicated the appropriateness of the classification variables, and application of a varimax rotation suggested a sixcomponent solution that explained over $82 \%$ of the total variance, with the first component explaining about $18 \%$ of the variance and the sixth component explaining roughly eight percent. With fewer than 120 LMSs in the sample, factor loadings considered statistically significant were those with absolute values greater than or equal to 0.55 [35]. All 14 variables displayed communalities above 0.50 , indicating that, for each variable, the six components explain the majority of their variance. Each variable exhibited a significant factor loading in a single component; no variables lacked a significant loading, and no variables displayed significant loadings in multiple components. Thus, a strong factor solution exists, supporting the study's classification variables (Table 2). 


\section{Table 2}

Classification variable communality values and component matrix results

\begin{tabular}{|c|c|c|c|c|c|c|c|}
\hline Variable & Communalities & \multicolumn{6}{|c|}{ Component } \\
\hline & & 1 & 2 & 3 & 4 & 5 & 6 \\
\hline Service Location Types & 0.839 & 0.866 & & & & & \\
\hline Case Mix Difference & 0.827 & & & 0.861 & & & \\
\hline Extreme Case Share & 0.787 & & & 0.854 & & & \\
\hline Birth Case Distribution & 0.896 & & & & & & 0.921 \\
\hline Geographic Reach & 0.914 & & & & 0.921 & & \\
\hline Geographic Spread & 0.921 & & & & 0.913 & & \\
\hline Hospitals & 0.826 & & & & & 0.841 & \\
\hline Horizontally Integrated Stages & 0.911 & 0.921 & & & & & \\
\hline Locations/Horizontally Integrated Stage & 0.532 & 0.564 & & & & & \\
\hline Vertically Integrated Stages & 0.882 & & 0.876 & & & & \\
\hline Upstream Vertical Integration Breadth & 0.832 & & 0.687 & & & & \\
\hline Downstream Vertical Integration Breadth & 0.812 & & 0.811 & & & & \\
\hline Hospital Transfer Difference & 0.759 & & & 0.628 & & & \\
\hline Duplication of Services & 0.794 & & & & & -0.802 & \\
\hline Percent of Variance Explained & & 17.754 & 16.302 & 14.411 & 13.006 & 12.909 & 7.997 \\
\hline
\end{tabular}

Note: Component values reflect rotated component matrix results using varimax rotation;

Component values indicate statistically significant loadings $(>10.550 \mid$, based upon 0.05 significance level and power level of $80 \%$ for sample size less than 120)

The single-linkage algorithm indicated the presence of a "chaining effect" across cluster solutions; thus, the single-linkage results were uninformative [35]. Examination of the dendrograms, agglomeration plots, and changes in agglomeration coefficients for the complete-linkage, average linkage, and Ward's method algorithms supported a five-cluster solution. Upon comparison of hierarchical algorithm results, the Ward's method best fit the data, which is consistent with scholars' preference for the Ward's method [9, 36]. Average values of the 14 standardized classification variables for each of these five solution groups were used as initial seeds for a nonhierarchical cluster analysis, the solution of which produced five groups with 45, 39, 16 , 9 , and 5 members, respectively. 
The final solution of the two-stage cluster analysis was validated through comparison to alternative cluster analysis results using different agglomeration methods, nonstandardized classification variables, random initial seeds, and factor scores. The results revealed a reliable final solution, with high levels of agreement across many of the compared solutions. ${ }^{5}$ Internal validation was also performed through multiple discriminant analysis using the groupings of the final cluster solution as the dependent variable and the 14 standardized classification variables as the independent variables. Applying a separate-groups covariance matrix for the classification process and defining prior probabilities according to cluster group size led to a 99.1\% correct classification rate that far exceeded the proportional chance criterion, indicating predictive accuracy of the discriminant analysis [35]. ${ }^{6}$

ANOVA tests were performed for each of the classification variables, and robust Welch and Brown-Forsythe tests were run on the equality of group means. Evidence of unequal variances and disparate group sizes led to Games-Howell tests, a preferred post-hoc procedure under such conditions [37], evaluating each pair of cluster groups for differences across each classification variable. ANOVA tests for separate classification variables reveal that each is significantly different across the taxonomic groups (Table 3 ). Both of the robust tests of equality of means obtain significant results at the 0.01 level for all classification variables but one. The lone exception, "Duplication of Services," had zero variance for one of the groups and was unanalyzable. The Games-Howell tests reveal that in only three instances did an individual variable comparison of one group's mean to means of each of the other groups lack a statistically significant difference between at least one of the compared pairs. 
Table 3

Taxonomic group mean values for classification variables

\begin{tabular}{|c|c|c|c|c|c|}
\hline Variable & $\begin{array}{c}\text { Lowly } \\
\text { Differentiated } \\
\text { \& Integrated } \\
(n=45)\end{array}$ & $\begin{array}{c}\text { Integrated \& } \\
\text { Concentrated } \\
\quad(n=39)\end{array}$ & $\begin{array}{c}\text { Highly } \\
\text { Differentiated } \\
\text { \& Integrated } \\
(n=16)\end{array}$ & $\begin{array}{c}\text { Dispersed } \\
\& \\
\text { Hospital- } \\
\text { Focused } \\
(n=9)\end{array}$ & $\begin{array}{c}\text { Vertically } \\
\text { Differentiated } \\
\text { \& Lowly } \\
\text { Integrated } \\
(n=5)\end{array}$ \\
\hline \multicolumn{6}{|l|}{ Horizontal Differentiation } \\
\hline Hospital Services* & $0.48^{\mathrm{bc}}$ & $0.69^{\text {ade }}$ & $0.76^{\text {ade }}$ & $0.52^{\mathrm{bc}}$ & $0.38^{\mathrm{bc}}$ \\
\hline Service Location Types* & $4.96^{b c}$ & $8.74^{\text {ade }}$ & $8.19^{\mathrm{ad}}$ & $3.67^{b c}$ & $4.40^{\mathrm{b}}$ \\
\hline Vertical Differentiation & & & & & \\
\hline Case Mix Difference* & $0.05^{\text {be }}$ & $0.14^{\text {ce }}$ & $0.47^{\mathrm{abd}}$ & $0.00^{\text {ce }}$ & $0.64^{\mathrm{abd}}$ \\
\hline Extreme Case Share* & $0.00^{\text {ce }}$ & $0.01^{\text {ce }}$ & $0.06^{\mathrm{ab}}$ & 0.02 & $0.06^{\mathrm{ab}}$ \\
\hline $\begin{array}{l}\text { Birth Case Distribution* } \\
\text { Spatial Differentiation }\end{array}$ & $0.04^{\text {be }}$ & $0.05^{\mathrm{ae}}$ & $0.04^{\mathrm{e}}$ & $0.04^{\mathrm{e}}$ & $0.11^{\mathrm{abcd}}$ \\
\hline Locations* & $11.84^{\mathrm{bcd}}$ & $33.05^{\text {ade }}$ & $37.44^{\text {ade }}$ & $6.44^{\mathrm{abc}}$ & $10.40^{\mathrm{bc}}$ \\
\hline Geographic Reach* & $17.80^{\mathrm{bcd}}$ & $26.11^{\text {ade }}$ & $30.12^{\text {ade }}$ & $64.65^{\text {abce }}$ & $12.85^{\mathrm{bcd}}$ \\
\hline $\begin{array}{l}\text { Geographic Spread* } \\
\text { Horizontal Integration }\end{array}$ & $12.30^{\mathrm{d}}$ & $11.38^{\mathrm{cd}}$ & $15.55^{\mathrm{bd}}$ & $45.90^{\text {abce }}$ & $11.89^{d}$ \\
\hline Hospitals* & $2.89^{b c}$ & $5.28^{\text {ade }}$ & $6.88^{\text {ade }}$ & $2.67^{b c}$ & $2.20^{\mathrm{bc}}$ \\
\hline Horizontally Integrated Stages* & $2.00^{\mathrm{bcd}}$ & $4.46^{\mathrm{ad}}$ & $3.94^{\mathrm{ad}}$ & $0.78^{a b c}$ & 2.00 \\
\hline $\begin{array}{l}\text { Locations / Horizontally Integrated Stage* } \\
\text { Vertical Integration }\end{array}$ & $3.02^{b c}$ & $5.78^{\text {ade }}$ & $6.73^{\text {ade }}$ & $1.50^{\mathrm{bc}}$ & $2.72^{\mathrm{bc}}$ \\
\hline Vertically Integrated Stages* & $10.98^{\mathrm{bcd}}$ & $12.97^{\mathrm{ae}}$ & $13.13^{\text {ae }}$ & $12.56^{\text {ae }}$ & $10.60^{\text {bcd }}$ \\
\hline Upstream Vertical Integration Breadth* & $0.54^{b c}$ & $0.76^{\text {ade }}$ & $0.82^{\text {ade }}$ & $0.59^{b c}$ & $0.40^{\mathrm{bc}}$ \\
\hline $\begin{array}{l}\text { Downstream Vertical Integration Breadth* } \\
\text { Coordination }\end{array}$ & $0.21^{b c}$ & $0.43^{\text {ae }}$ & $0.54^{\text {ade }}$ & $0.31^{c}$ & $0.20^{\mathrm{bc}}$ \\
\hline Hospital Transfer Difference* & $-0.00^{c}$ & $0.02^{c}$ & $0.10^{\mathrm{abd}}$ & $0.00^{c}$ & 0.00 \\
\hline Duplication of Services* & $0.79^{b c d}$ & $0.64^{\text {acd }}$ & $0.53^{\text {abde }}$ & $0.68^{\text {ce }}$ & $1.00^{\mathrm{abcd}}$ \\
\hline
\end{tabular}

Note: ANOVA test of significant differences in group means within dependent variable: ${ }^{*} p<0.01$

Games-Howell post-hoc test of significant differences in means between individual groups at $p<0.05$ level:

a=different from "Lowly Differentiated \& Integrated" LMSs;

$\mathrm{b}=$ different from "Integrated \& Concentrated" LMSs;

$\mathrm{c}=$ different from "Highly Differentiated \& Integrated" LMSs;

$\mathrm{d}=$ different from "Dispersed \& Hospital-Focused" LMSs;

e=different from "Vertically Differentiated \& Lowly Integrated" LMSs. 


\subsection{Group profiles}

Analysis of the classification variables' mean values across the five taxonomic groups allows for comparison of LMS forms, recognizing either "high" (with no other groups' means significantly higher), "low" (with no other groups' means significantly lower), or "moderate" (with other groups' means both significantly higher and lower) levels for each variable (Table 4).

\section{Table 4}

Categories of taxonomic group means for classification variables

\begin{tabular}{|c|c|c|c|c|c|}
\hline Variable & $\begin{array}{c}\text { Lowly } \\
\text { Differentiated } \\
\& \text { Integrated } \\
(n=45)\end{array}$ & $\begin{array}{l}\text { Integrated \& } \\
\text { Concentrated } \\
\quad(n=39)\end{array}$ & $\begin{array}{c}\text { Highly } \\
\text { Differentiated } \\
\text { \& Integrated } \\
(n=16)\end{array}$ & $\begin{array}{l}\text { Dispersed } \\
\text { \& Hospital- } \\
\text { Focused } \\
(n=9)\end{array}$ & $\begin{array}{c}\text { Vertically } \\
\text { Differentiated } \\
\text { \& Lowly } \\
\text { Integrated } \\
(n=5)\end{array}$ \\
\hline \multicolumn{6}{|l|}{ Horizontal Differentiation } \\
\hline Hospital Services & LOW & $\mathrm{HIGH}$ & $\mathrm{HIGH}$ & LOW & LOW \\
\hline Service Location Types & LOW & $\mathrm{HIGH}$ & $\mathrm{HIGH}$ & LOW & LOW \\
\hline \multicolumn{6}{|l|}{ Vertical Differentiation } \\
\hline Case Mix Difference & LOW & LOW & $\mathrm{HIGH}$ & LOW & $\mathrm{HIGH}$ \\
\hline Extreme Case Share & LOW & LOW & HIGH & -- & $\mathrm{HIGH}$ \\
\hline Birth Case Distribution & LOW & MODERATE & LOW & LOW & $\mathrm{HIGH}$ \\
\hline \multicolumn{6}{|l|}{ Spatial Differentiation } \\
\hline Locations & MODERATE & $\mathrm{HIGH}$ & $\mathrm{HIGH}$ & LOW & MODERATE \\
\hline Geographic Reach & LOW & MODERATE & MODERATE & $\mathrm{HIGH}$ & LOW \\
\hline Geographic Spread & LOW & LOW & MODERATE & $\mathrm{HIGH}$ & LOW \\
\hline \multicolumn{6}{|l|}{ Horizontal Integration } \\
\hline Hospitals & LOW & $\mathrm{HIGH}$ & $\mathrm{HIGH}$ & LOW & LOW \\
\hline Horizontally Integrated Stages & MODERATE & $\mathrm{HIGH}$ & $\mathrm{HIGH}$ & LOW & -- \\
\hline Locations / Horizontally Integrated Stage & LOW & $\mathrm{HIGH}$ & $\mathrm{HIGH}$ & LOW & LOW \\
\hline \multicolumn{6}{|l|}{ Vertical Integration } \\
\hline Vertically Integrated Stages & LOW & $\mathrm{HIGH}$ & HIGH & $\mathrm{HIGH}$ & LOW \\
\hline Upstream Vertical Integration Breadth & LOW & $\mathrm{HIGH}$ & $\mathrm{HIGH}$ & LOW & LOW \\
\hline Downstream Vertical Integration Breadth & LOW & $\mathrm{HIGH}$ & $\mathrm{HIGH}$ & LOW & LOW \\
\hline Coordination & & & & & \\
\hline Hospital Transfer Difference & LOW & LOW & HIGH & LOW & -- \\
\hline Duplication of Services & MODERATE & MODERATE & LOW & MODERATE & $\mathrm{HIGH}$ \\
\hline
\end{tabular}


The first group, "Lowly Differentiated and Integrated" LMSs, includes the largest share of LMSs, about $40 \%$. They maintain relatively low levels of horizontal differentiation and exhibit low levels of vertical differentiation by case complexity and case type. These systems operate a moderate number of locations, display a relatively limited geographic reach, and exhibit a concentrated geographic spread. They also exhibit relatively low levels of horizontal and vertical integration and show limited coordination of activities across their facilities.

The second group, "Integrated and Concentrated" LMSs, includes just over one-third of the sample's LMSs. They are moderately differentiated, exhibiting high levels of horizontal differentiation but relatively low to moderate levels of vertical differentiation. These LMSs maintain a high number of service locations, encompass moderate distances within their markets, and exhibit a concentrated spread, with relatively short average distances from service locations to member hospitals. They are also highly integrated both horizontally and vertically but display moderate levels of coordination.

Representing fourteen \% of the sample, the systems in the third group are "Highly Differentiated and Integrated" LMSs. They exhibit high levels of horizontal differentiation as well as vertical differentiation (specifically by case complexity). These systems are spatially differentiated, operating many service locations with a moderate geographic reach and moderately dispersed configurations. They are highly integrated both horizontally and vertically, exhibiting the highest degree of coordination among the taxonomy's LMS forms.

The fourth group, "Dispersed and Hospital-Focused" LMSs, represents just under $8 \%$ of the sample. They display low levels of horizontal and vertical differentiation. However, their spatial arrangements are unique because they operate in relatively few locations - typically hospitals - yet their facilities are widely dispersed with an extensive geographic reach. They also exhibit low levels of horizontal integration and low to moderate levels of vertical integration and coordination across their facilities.

Systems in the fifth and smallest group are "Vertically Differentiated and Lowly Integrated" LMSs. They display low levels of horizontal 
differentiation yet are highly vertically differentiated by case complexity and service type. In contrast, these LMSs operate a moderate number of locations and maintain concentrated configurations with limited geographic reach. They also exhibit low levels of horizontal integration, vertical integration, and coordination across their facilities.

\section{Discussion}

This study's taxonomy provides a foundational understanding of LMS forms based on their hospital- and non-hospital-based components, and the evident diversity among the five solution groups illustrates the importance of accounting for such heterogeneity in research and policy analysis rather than examining LMSs as a homogenous form. These findings also support theoretically motivated arguments that differentiation and integration are key dimensions of organizational structure [14], extending to the interorganizational structures of LMSs, while configuration and coordination - dimensions of differentiation and integration, respectively, as described by Porter [15] - also clearly describe and distinguish LMS forms, emphasizing geographic considerations to conceptualize health care organizations. Such geographic considerations are critical in this study to define hospital systems at local levels and evaluate LMSs' spatial arrangements of hospitals and nonhospital-based service locations.

A comparison of the LMS groups derived from this analysis to the widelyrecognized hospital system categories of the AHA Annual Survey dataset, developed by Bazzoli and colleagues [9], reveals some consistencies between the taxonomies. For example, there is a disproportionate share of "Lowly Differentiated and Integrated" LMSs categorized as "Decentralized Health Systems" or "Independent Hospital Systems" in the AHA taxonomy, noted for their moderate to low differentiation and lack of vertical relationships, while only one "Lowly Differentiated and Integrated" LMS was also categorized in the AHA taxonomy as a "Centralized Health System," a group recognized for moderate to high service differentiation. We also observed most of the "Highly Differentiated and Integrated" LMSs categorized as either "Centralized Health Systems," "Centralized Physician/Insurance 
Health Systems," or "Moderately Centralized Health Systems" in the AHA taxonomy, noted for their moderate to high service differentiation, while few are assigned to the AHA categories reflecting lower degrees of differentiation or integration. Results of a Fisher's exact test suggest a statistically significant association $(p<0.05)$ between our sample LMSs' assignments to the AHA taxonomic groups and their assignments to one of the five LMS forms identified in this study. Furthermore, a Cramer's V measure of the association between the taxonomies' assignments for the sample LMSs indicates a moderate association (0.271).

At the same time, examination of the two taxonomies reveals important discrepancies, with LMSs in each single grouping within our study's taxonomy identified across multiple AHA taxonomic categories. Notably, LMSs that are consolidated as a single system and classified within the same group in the AHA categories are shown in this study to present distinctive forms from one another. For example, the varied "subsystems" of regional and national hospital organizations (e.g., HCA, Tenet, CHRISTUS Health) operating as LMSs in different local markets were categorized across different taxonomic groups, supporting arguments that local multihospital systems - including the local subsystems of regional or national hospital chains - merit distinction when classifying hospital system forms, as local market characteristics and phenomena influence system operations and strategies [38].

Thus, these results build upon past efforts to categorize hospital-based systems, as previous taxonomic efforts that did not identify and separate LMSs within their larger corporate systems overlooked the potential heterogeneity of a system's LMS forms across its separate markets. This taxonomy is also distinct in its emphasis on geographical considerations, accounting for LMSs' spatial arrangements and non-hospital-based service locations as key classification variables. Indeed, we observe spatial arrangements and strategies relating to the operation and coordination of service locations as distinguishing elements of LMS forms. Although past studies and datasets of hospital-based systems have typically not recognized their non-hospital-based components, they are critical elements to identify and consider with LMSs today, as non-hospital-based service locations allow 
LMSs to expand access and provision of services throughout their markets [12]. Finally, this taxonomy is an updated depiction of hospital system activity from previous taxonomic efforts, which utilized data from the late 20th century, prior to the influences of the recent geographic expansion race and health care reform trends.

Having developed a taxonomy that describes common LMS forms, an important question for future research is, how do we explain the differences observed across these LMS forms? The findings of the taxonomic analysis revealing variation in differentiation and integration among LMSs at the local level - lend support to Lawrence and Lorsch's [14] seminal arguments, but are there reasons why we see such varying degrees of differentiation and integration among LMSs across different local markets? Organization theory speaks directly to such questions, and we suggest - as others have - that such questions demand the application of multiple perspectives to understand more fully the complex and myriad phenomena influencing LMSs' differentiation and integration activities. For example, Shay and colleagues [3] draw from numerous sources and perspectives (e.g., contingency theory, strategic management theory, institutional theory, transaction cost economics, resource dependence theory, etc.) and point to a variety of potential determinants of LMS forms, including: local environmental forces (e.g., population demography, epidemiology, employers); local market actors (e.g., competitors, providers, payers); organizational characteristics (e.g., size, history); local environmental contingencies (e.g., munificence, dynamism, geography); and, motivational factors (e.g., power, efficiency, competitive posturing, industry evolution, institutional pressures). Organization theorists suggest that each of these locally observed factors, or "contingencies," may explain why different LMSs would pursue varying degrees of differentiation and integration, as different structures and strategies allow LMSs to fit their specific tasks and environmental demands best $[14,15]$. In the same way, we anticipate that differences among LMS forms may be tied to differences in their local markets, including different local environmental forces, market actors, environmental contingencies, and motivational factors. For example, consideration of isomorphic pressures - as described by institutional theory and population ecology perspectives - suggests that a LMS's adoption of a specific form may be more likely if other LMSs competing in the same 
market also exhibit that form. Or, consideration of a local system's size - a key organizational factor addressed by numerous perspectives such as resource dependence theory - may lead one to expect that larger organizations would be more capable of acquiring and maintaining the resources needed to effectively manage LMS forms characterized as more diverse in their services, components, and locations (e.g., Highly Differentiated \& Integrated LMSs). However, such hypotheses must be properly examined and tested in future studies specifically examining organizational and environmental factors that account for differences between LMS categories. Furthermore, such recognition of local factors as potential determinants of multihospital system forms lends further support to the importance of studying and identifying multihospital system activities at local levels.

For health care managers, consideration of these factors may assist in the formulation of their own organization's strategies as well as the characterization and assessment of competing LMSs' strategic activities. In addition, managers' awareness of LMS forms may assist their evaluation of growth opportunities, competitive and environmental threats, and organizational weaknesses, and identifying the desirable characteristics of certain LMS forms may provide managers with a better recognition of other organizations that would be suitable for partnership or emulation. This becomes a particularly important endeavor in an industry that continues to consolidate, that applies increased pressures for providers to grow throughout the continuum of care, and that increasingly calls for providers to adopt population health models and care for their local communities outside of hospital walls.

We anticipate LMSs will influence the implementation and outcomes of U.S. health care reform efforts emphasizing the coordination of services across health care settings and throughout the continuum of care. Yet, recent studies [e.g., 7, 39] shed doubt that hospital-based providers can meet policymakers' aims for improved care coordination. With the majority of LMSs in this study exhibiting low levels of differentiation, integration, and coordination, such skepticism may be warranted. Future studies may examine which LMS forms effectively meet health care reform goals, as well as whether specific 
LMS forms realize a regionalized model of care delivery - a vision of hierarchical coordination a century in the making $[2,40]$.

Addressing the potential of LMSs to inform health policy design and health planning, Luke [2: 194] suggests that LMSs display great potential to usher in regionally coordinated health care in the U.S. as they "now form the basis for regional organization and management of acute care and other services." Similarly, Porter and Lee [41: 66] promote the strategic geographic expansion of "superior" providers through a hub-and-spoke model, enabling the provision of vertically differentiated and coordinated care in diverse locations within a market. Descriptions of such models resemble the characteristics of "Highly Differentiated and Integrated" LMSs, and policymakers may consider ways to promote such forms in their design of health policy as well as to further evaluate the association between such forms and the effective and efficient provision of health services. And, as international health care delivery systems increasingly turn to such regionalized models "as a strategy for addressing the consequences of system fragmentation," international health policymakers may find interest in examining LMS forms to "improve system performance" and consider how service delivery may be restructured and reconfigured to promote coordination [2: 200].

These results may also be employed to evaluate health policies, particularly as they relate to population health management and value-based care. Given their scale and importance as health care providers at the local level, LMSs are well-positioned to respond to recent U.S. health policy reform efforts, including the accountable care organization (ACO) model. ACO proponents value the organization of health services from a local perspective, believing improvements in quality and cost control are best achieved through coordination across the care continuum among defined groups of local hospitals and health service providers [e.g., 42]. LMSs displaying arrangements with service components coordinated throughout the care continuum, including "Highly Differentiated and Integrated" LMSs, exemplify such ideals, but do such forms embrace or participate in ACO models, and do they succeed in achieving the ambitious goals of the ACO concept? Are certain LMS forms equipped to manage the health of their 
local communities and succeed under value-based financing given variations in differentiation, integration, and spatial arrangements? And, given their variation in spatial arrangements and the ties to access in their local markets, what may be the association between different LMS forms and cost or quality outcomes? Are certain LMS forms better positioned to address the "iron triangle" of cost, access, and quality concerns in health care?

\subsection{Limitations}

We acknowledge several study limitations. First, identification of LMSs' spatial boundaries using a defined radius is imprecise when assigning hospitals to local systems. However, this decision acknowledges the underrepresentation of LMSs and their components when adopting urban boundaries; thus, the 150-mile radius boundary was applied, consistent with recent LMS studies [3]. Within the study sample, over $83 \%$ of the hospitals operated within 50 miles of their LMSs' lead hospital, and roughly $97 \%$ operated within 100 miles of their system's largest hospital. A total of 13 sample LMSs included a hospital member located greater than 100 miles from their system's largest hospital, and during primary data collection, examination of these hospital locations suggested their involvement as participating facility members within the recognized LMS.

Also, obtaining information regarding LMS components, configurations, and activities relied upon both providers' accurate reporting during primary data collection and accurate information provided in secondary datasets. Eight LMSs were excluded from the study sample due to missing data. Additionally, 28 LMSs lacked facility-level data for specific hospital members, but sufficient information was available for their remaining hospital members for necessary measures, and these systems were thus maintained in the sample. Furthermore, the years represented across the study's data sources were inconsistent. Primary data sources reflected LMSs as of 2012, and Intellimed data for five of the six states also reflected hospital-level operations in 2012. However, for LMSs based in Texas, Intellimed data covered July 2011 through June 2012. Data included from the AHA Annual Survey primarily represented LMSs' services and 
operations as of 2011, but in some instances, required substitution of 2010 data.

The constructs of differentiation and integration are complex and challenging to operationalize. Given this and the limitations of available data, a system's differentiation and integration may not have been as well captured as desired. For example, using birth case distribution as the indicator of vertical differentiation by service type may have neglected other evidence of vertical differentiation by service type. Second, the evaluation of inter-hospital coordination comparing transfer admissions between a LMS's lead hospital and its non-lead facilities served as a proxy measure of coordination, but data sources could not distinguish transfers and admissions from non-LMS hospitals [3]. Third, LMSs' integration activities required same-system ownership, potentially disregarding evidence of integration with providers outside of ownership arrangements. Fourth, integration was evaluated according to LMSs' health care services and did not consider insurance products or financial services. Fifth, measurements of differentiation and integration between lead and non-lead facilities assumed the designation of a single lead hospital within each LMS. In some cases, a system may not designate a single facility as its lead hospital, and in other cases, the largest facility may not necessarily operate as a system's lead hospital.

Finally, the six-state focus limited the generality of the results and size of the study's sample. Although this focus was the result of restricted access to Intellimed admissions data for the six states represented in the sample, an expansion of the study to include LMSs representing more states, particularly from the Midwest and Northeast regions of the U.S., and to produce greater sample size, is desired. Related to this, reliance upon primary as well as proprietary data sources, such as Intellimed, poses a considerable challenge for future study replication efforts. Furthermore, important state-level factors that could contribute to study findings, such as states' regulatory and financial environments, were not controlled for in the study. 


\section{Conclusion}

This taxonomy provides a practical groundwork for data collection and analysis of LMSs. Additional analysis by the lead author as part of a broader study examining LMSs provides external validation for the LMS taxonomy, as more than 20 theoretically derived measures - external from the classification variables previously presented - were observed to exhibit significant differences across the five LMS forms [43]. Given such validation, future studies should update the catalog and taxonomy, allowing for longitudinal evaluation of changes in LMS components and forms and ensuring the relevance and validity of the taxonomic groups. Future research can also examine the association between LMS forms and issues such as medical care spending, efficiency, access to care, and quality of care, among others. Local multihospital systems, not individual hospitals, are now the dominant providers of health care services in local markets throughout the U.S., and their contribution to health delivery must not be neglected.

\section{Notes}

1 We recognize the potential for confusion between Porter's use of the term "configuration" and others' approaches to the term "configuration," including the shape of organizational role structures [19] as well as in relation to configuration or archetype theory [e.g., 20, 21]. For this reason, we use the term "spatial differentiation" to refer to the concepts described in Porter's definition of configuration.

2 Figure 1 is adapted from similar depictions of the continuum of care by Conrad and colleagues [23: 54, 29: 493], Mick and Conrad [26: 351], and Clement [28: 103]. These depictions recognize different stages along the continuum of care, represented in Fig. 1 as "Inputs to Services," "Direct Service Outputs," "Episodic Service Outputs," and "Chronic Service Outputs." Within each of these stages, different categories of service or product settings are identified, as shown in Fig. 1. Examples of "Education of Labor" sites operated by LMSs include nursing schools, therapy schools, and management schools, and "Medical Equipment" sites include durable medical equipment vendor locations. "Ancillary Services" settings include diagnostic laboratories, diagnostic imaging centers, and pharmacies, while "Wellness \& Health Promotion" sites include fitness and wellness centers, diabetes clinics, and pregnancy testing and education facilities. "Primary Care" locations refer to primary care physician practices and clinics, and "Specialty Physician Care" locations refer to specialty physician practices and clinics. Examples of "Acute Outpatient Care" settings include ambulatory surgery centers, sleep clinics, and wound care clinics. "Non-Physician Provider Care" locations refer to sites providing 
care primarily through the services of non-physician providers, such as retail clinics, outpatient rehabilitation clinics, behavioral health clinics, and occupational health clinics. "Urgent \& Emergency Care" sites include freestanding emergency centers and urgent care clinics. "General Hospital Inpatient Care” refers to services provided within general, acute care hospitals, and "Specialty Hospital Inpatient Care" refers to services provided within specialty hospitals such as heart hospitals and surgical hospitals. Examples of "Short-term Inpatient Rehab \& Nursing" settings include inpatient rehabilitation facilities and behavioral health hospitals, while "Longterm Inpatient Rehab \& Nursing" sites include long-term acute care hospitals and skilled nursing facilities. "Outpatient Rehab \& Nursing" refers to LMS services such as home health and comprehensive outpatient rehabilitation facilities, and "Extended Care \& Living" locations are settings such as long-term care facilities, assisted living facilities, continuing care retirement communities, adult day care centers, and hospice homes. "Multi-Service Outpatient Centers" may include varied combinations of ancillary, wellness $\&$ health promotion, primary care, acute $\&$ specialty outpatient care, non-physician provider care, or urgent and emergency care services.

3 Additional information regarding the study's data sources, including substitution of AHA 2010 Annual Survey data and instances in which LMSs lacked observations for individual facilities, is available upon request.

4 A detailed listing of each service variable and its assigned stage, as well as a listing of corresponding service location types identified in primary data collection, is available upon request.

5 A comparison of agreement rates between the final solution and alternative cluster analysis results is available upon request.

6 Separate discriminant analyses were also performed for cross-validation purposes, using a within-groups covariance matrix, equal prior probabilities, and split-sample validation methods. Each of the classification rates obtained from these multiple discriminant analyses greatly exceeded the recommended classification accuracy, indicating that the final cluster groupings are internally valid and reliable. A comparison of these results is available upon request.

\section{Acknowledgments}

The authors wish to thank Dr. Carl F. Ameringer, Dr. Roice D. Luke, Dr. Carolyn A. Watts, and anonymous reviewers for their valuable comments on previous versions of this article. 


\section{References}

1. Luke RD, Ozcan YA (2013) Health care strategic decision making. In: Gass SI, Fu MC (eds), Encyclopedia of operations research and management science, 3rd edn. Springer, New York, pp 684-693

2. Luke RD (2010) System transformation: USA and international strategies in healthcare organisation and policy. Int J Public Pol 5:190203

3. Shay PD, Luke RD, Mick SSF (2014) Differentiated, integrated, and overlooked: Hospital-based clusters. In: Mick SSF, Shay PD (eds), Advances in health care organization theory, 2nd edn. Jossey-Bass, San Francisco, pp 179-203

4. Cuellar AE, Gertler PJ (2003) Trends in hospital consolidation: The formation of local systems. Health Aff 22(6): 77-87

5. Luke RD, Luke T, Muller N (2011) Urban hospital 'clusters' do shift high-risk procedures to key facilities, but more could be done. Health Aff 30: $1743-1750$

6. Sikka V, Luke RD, Ozcan YA (2009) The efficiency of hospital-based clusters: Evaluating system performance using data envelopment analysis. Health Care Manage Rev 34: 251-261

7. Trinh HQ, Begun JW, Luke RD (2014) Service duplication within urban hospital clusters. Health Care Manage Rev 39: 41-49

8. Shortell SM, Bazzoli GJ, Dubbs NL, Kralovec P (2000) Classifying health networks and systems: Managerial and policy implications. Health Care Manage Rev 25(4): 9-17

9. Bazzoli GJ, Shortell SM, Dubbs N, Chan C, Kralovec P (1999) A taxonomy of health networks and systems: Bringing order out of chaos. Health Serv Res 33: 1683-1717

10. Lewis BL, Alexander J (1986) A taxonomic analysis of multihospital systems. Health Serv Res 21:29-56

11. Luke RD (1991) Spatial competition and cooperation in local hospital markets. Med Care Rev 48: 207-237 
12. Carrier ER, Dowling M, Berenson RA (2012) Hospitals' geographic expansion in quest of well-insured patients: Will the outcome be better care, more cost, or both? Health Aff 31: 827-835

13. Aldenderfer JA, Blashfield RK (1984) Cluster analysis. Sage University Paper Series on Quantitative Applications in the Social Sciences, 07-044. Sage Publications, Beverly Hills, CA

14. Lawrence PR, Lorsch JW (1967) Organization and environment: Managing differentiation and integration. Harvard University Press, Boston

15. Porter ME (1986) Competition in global industries: A conceptual framework. In: Porter ME (ed), Competition in global industries. Harvard Business School Press, Boston, pp 15-60

16. Mileti DS, Gillespie DF, Haas JE (1977) Size and structure in complex organizations. Soc Forces 56: 208-217

17. Goldman P (1973) Size and differentiation in organizations: A test of theory. Pacific Soc Rev 16: 89-105

18. Tay A (2003) Assessing competition in hospital care markets: The importance of accounting for quality differentiation. RAND J Econ 34 : 786-814

19. Pugh DS (1973) The measurement of organization structures: Does context determine form? Organ Dyn 1(4): 19-34

20. Greenwood R (2008) Configuration theory. In: Clegg SR, Bailey JR (eds), International encyclopedia of organization studies. Sage Publications, Thousand Oaks, CA, pp 248-252

21. Miller D (1986) Configurations of strategy and structure: Towards a synthesis. Strategic Manage J 7: 233-249

22. Banner DK, Gagne TE (1995) Designing effective organizations: Traditional and transformational views. Sage Publications, Thousand Oaks, CA 
23. Conrad DA, Mick SS, Watts-Madden C, Hoare G (1988) Vertical structures and control in health care markets: A conceptual framework and empirical review. Med Care Rev 45: 49-100

24. Snail TS, Robinson JC (1998) Organizational diversification in the American hospital. Annu Rev Public Health 19: 417-453

25. Gillies RR, Shortell SM, Anderson DA, Mitchell JB, Morgan KL (1993) Conceptualizing and measuring integration: Findings from the health systems integration study. Hosp Health Serv Adm 38: 467-489 26. Mick SS, Conrad DA (1988) The decision to integrate vertically in health care organizations. Hosp Health Serv Adm 33: 345-360

27. Morrison A, Roth K (1993) Relating Porter's

configuration/coordination framework to competitive strategy and structural mechanisms: Analysis and implications. J Manage 19: 797-818 28. Clement JP (1988) Vertical integration and diversification of acute care hospitals: Conceptual definitions. Hosp Health Serv Adm 33: 99-110 29. Conrad DA (1993) Coordinating patient care services in regional health systems: The challenge of clinical integration. Hosp Health Serv Adm 38: 491-508

30. Jones SG, Ashby AJ, Momin SR, Naidoo A (2010) Spatial implications associated with using Euclidean distance measurements and geographic centroid imputation in health care research. Health Serv Res 45: 316-327

31. Luke RD (1992) Local hospital systems: Forerunners of regional systems? Front Health Serv Manage 9(2): 3-51

32. Dranove D, Shanley M, Simon C (1992) Is hospital competition wasteful? RAND J Econ 23: 247-262

33. Newhouse RP, Mills ME, Johantgen M, Pronovost PJ (2003) Is there a relationship between service integration and differentiation and patient outcomes? Int J Integr Care 3(10): 1-13

34. Hubert L, Arabie P (1985) Comparing partitions. J Classif 2: 193-218 
35. Hair JF, Black WC, Babin BJ, Anderson RE, Tatham RL (2006) Multivariate data analysis, 6th edn. Pearson Prentice Hall, Upper Saddle River, NJ

36. Punj G, Stewart DW (1983) Cluster analysis in marketing research: Review and suggestions for application. J Marketing Res 20: 134-148

37. Jaccard J, Becker MA, Wood G (1984) Pairwise multiple comparison procedures: A review. Psychol Bull 96: 589-596

38. Luke RD, Wholey DR (1999) Commentary: On 'A taxonomy of health networks and systems: Bringing order out of chaos.' Health Serv Res 33: 1719-1725

39. Burns LR, Wholey DR, McCullough JS, Kralovec P, Muller R (2012) The changing configuration of hospital systems: Centralization, federalization, or fragmentation? In: Friedman LH, Savage GT, Goes J (eds), Advances in health care management, Volume 13: Annual review of health care management: Strategy and policy perspectives on reforming health systems. Emerald Group Publishing, Bingley, UK, pp $189-232$

40. Fox DM (1986) Health policies, health politics: The British and American experience, 1911-1965. Princeton University Press, Princeton, $\mathrm{NJ}$

41. Porter ME, Lee TH (2013) The strategy that will fix health care. Harvard Bus Rev 91(10): 50-70

42. Shortell SM, Casalino LP (2008) Health care reform requires accountable care systems. JAMA 300: 95-97

43. Shay PD (2014) More than just hospitals: an examination of cluster components and configurations. Dissertation, Virginia Commonwealth University 